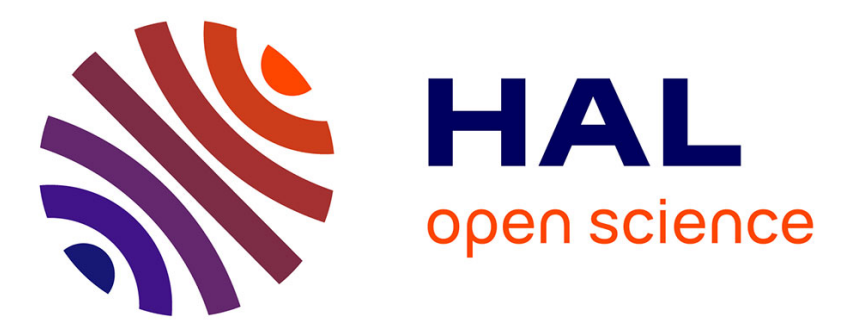

\title{
A single events microkinetic model for hydrocracking of vacuum gas oil
}

Pierre J. Becker, Nadège Serrand, Benoît Celse, Denis Guillaume, H Dulot

\section{To cite this version:}

Pierre J. Becker, Nadège Serrand, Benoît Celse, Denis Guillaume, H Dulot. A single events microkinetic model for hydrocracking of vacuum gas oil. Computers \& Chemical Engineering, 2017, 98, pp.70 - 79. 10.1016/j.compchemeng.2016.11.035 . hal-01519925

\section{HAL Id: hal-01519925 \\ https://hal.science/hal-01519925}

Submitted on 9 May 2017

HAL is a multi-disciplinary open access archive for the deposit and dissemination of scientific research documents, whether they are published or not. The documents may come from teaching and research institutions in France or abroad, or from public or private research centers.
L'archive ouverte pluridisciplinaire HAL, est destinée au dépôt et à la diffusion de documents scientifiques de niveau recherche, publiés ou non, émanant des établissements d'enseignement et de recherche français ou étrangers, des laboratoires publics ou privés. 


\title{
A Single Events Microkinetic Model for Hydrocracking of Vacuum Gas Oil
}

\author{
P.J. Becker ${ }^{1}$, N. Serrand ${ }^{1}$, B. Celse ${ }^{*}$, D.Guillaume ${ }^{1}$ H. Dulot $^{2}$ \\ 1- IFP Energies Nouvelles - Rond Point de l'échangeur de Solaize, BP 3, 69360 Solaize, France \\ 2- AXENS - 89, boulevard Franklin Roosevelt - BP 50802,95208 Rueil-Malmaison, France
}

*: corresponding author: Benoit.celse@ifpen.fr

\begin{abstract}
The single events microkinetic modeling approach is extended to include saturated and unsaturated cyclic molecules, in addition to straight chained paraffins. The model is successfully applied to hydrocracking (HCK) of a hydrotreated Vacuum Gas Oil (VGO) residue in a pilot plant, under industrial operating conditions, on a commercial bi-functional catalyst. The molecular composition of the VGO feed is obtained by reconstruction based on a combination of analytical data (SIMDIS, GCxGC, mass spectroscopy). The necessary extensions to the single events methodology, which has previously only been applied to much simpler reacting systems (i.e. HCK of paraffins) are detailed in this work. Feeds typically used in the petrochemical industry typically contain a far more complex mixture of hydrocarbons, including cyclic species (i.e. naphtenes \& aromatics). A more complex reaction network is therefore required in order to apply a single events model to such feeds. Hydrogenation, as well as endo- and exo-cyclic reactions have been added to the well-known acyclic $\beta$-scission and PCP-isomerization reactions. A model for aromatic ring hydrogenation was included in order to be able to simulate the reduction in aromatic rings, which is an important feature of HCK units. The model was then applied to 8 mass balances with a wide range of residue conversion (20-90\%). The single events model is shown to be capable of correctly simulate the macroscopic effluent characteristics, such as residue conversion, yield structure, and weight distribution of paraffinic, naphthenic, and aromatic compounds in the standard cuts. This validates the overall model. The single events model provides far more detail about the fundamental chemistry of the system. This is shown in a detailed analysis of the reaction kinetics. The evolution of molecule size (i.e. carbon number), number of saturated/unsaturated rings, or the ratio of branched and un-branched species can be followed along the reactor. This demonstrates the explanatory power of this type of model. Calculations are performed on the IFPEN high performance computing cluster, with parallelization via MPI (message passing interface). This was very useful in order to reduce time consuming problems especially for the parameter fitting step.
\end{abstract}




\section{Introduction}

A single events microkinetic model is applied to the Hydrocracking (HCK) of a hydrotreated Vacuum Gas Oil (VGO) feed. The single events methodology, which was first developed in the 1980s by Baltanas et al. [1], as a method of capturing the fundamental chemistry of the HCK process. A number of studies detailing the application and on-going development of this methodology have since been published [2-10]. These studies are essentially limited to long chain alkanes. Industrial feedstocks contain, however, a far more complex mixture of hydrocarbons, including (poly-) cyclic species such as naphtenes, aromatics, and naphtaneo-aromatics.A typical hydrotreated VGO feed contains, 20 - 30 $\% \mathrm{w} / \mathrm{w}$ paraffins, $50-80 \% \mathrm{w} / \mathrm{w}$ naphtenes, and $10-20 \% \mathrm{w} / \mathrm{w}$ aromatics. The high concentration of cyclic shows that the extension to the single events model is indispensable for the simulation of such feeds. This must be taken into account by a microkinetic model intended to be useful for simulation of industrial HCK units. The model presented here is an extension of previous single events models to saturated and unsaturated cyclic hydrocarbons, and the specific reactions associated with such molecules. The model is shown to be capable of simulating HCK of a typical hydrotreated VGO feed in a pilot plant at industrial operating conditions.

A detailed reaction network, based on the decomposition of the feed according to carbon number and 19 chemical families is constructed. The model is then used to simulate hydrocracking on a commercial catalyst industrial operating conditions, in a pilot plant. The model strategy is outlined in Figure 1. The molecular reconstruction of the feed, based on experimental measurements is the input of the kinetic model. The macroscopic effluent characteristics are then reconstructed from the individual molecules from single events simulation output. This can then be compared to the experimentally measured macroscopic effluent characteristics. 


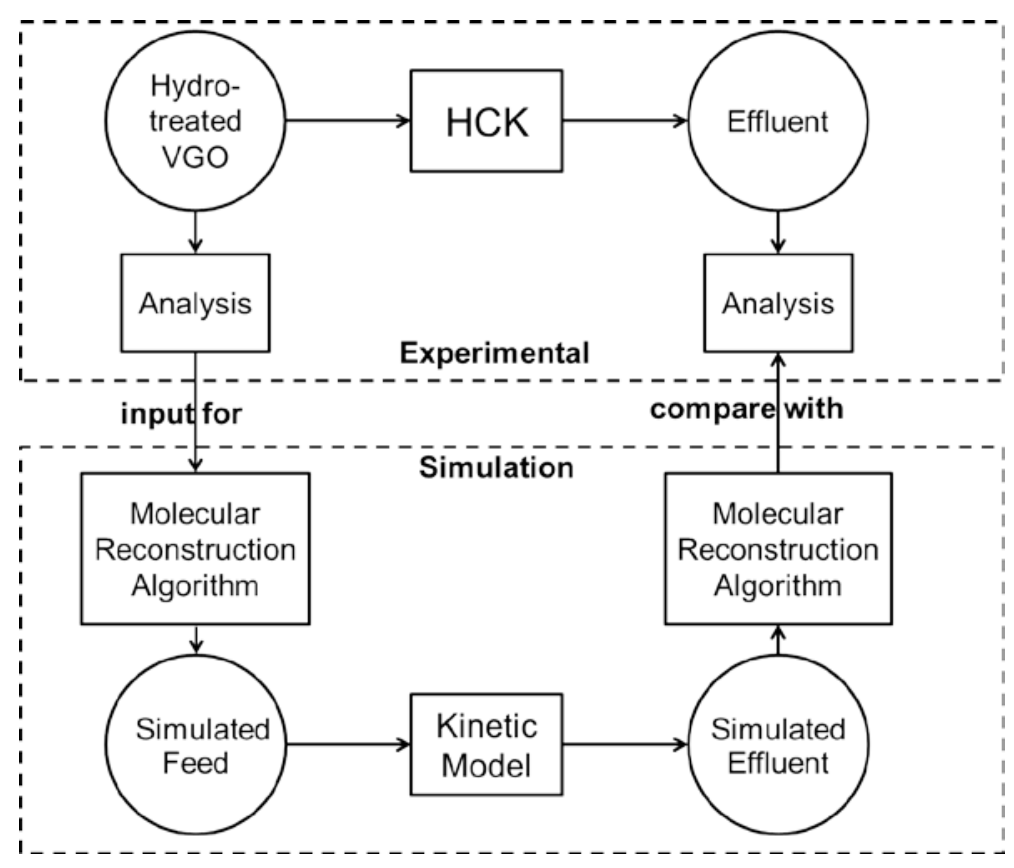

Figure 1 Outline of the model strategy used in this work

The motivations for the application of a microkinetic model to a real hydrocracking process is to capture the fundamental chemistry of this complex system in better detail than can be provided by, for example, continuous- or discrete lumping techniques. Moreover, in order to reduce time consuming problems, a dedicated implementation to super calculator is required.

This paper is structured as follows: The hydrocracking (HCK) process, catalyst, as well as an overview of recent advances in HCK modelling is presented in section 2. The molecular library and feed reconstruction algorithm is outlined in section 3. The methodology of the single events microkinetic model is described in section 4. The set-up of the pilot plant and the available experimental data is briefly presented in section 5.1, and the use of high performance computing is described in section 5.2. The simulation results are given in the section 6. This final section is divided as follows: section 6.1 outlines the kinetic parameter identification, sections 6.2 and 6.3 focus on the validation of macroscopic effluent characteristics, and section 6.4 gives a detailed insight into reaction kinetics. Concluding remarks are provided in section 7. 


\section{The Hydrocracking Process}

\subsection{Process Description}

Hydrocracking is a well-established, flexible technology for the processing of petrochemical feedstocks into high-quality products [11-14]. The increasing interest for hydrocracking unit in today's oil refining industry is explained by the continuously growing demand of middle distillates with excellent product quality, coupled with the depletion of traditional crude oil resources $[14,15]$. This process allows to convert heavy, low-value fractions such as Vacuum Gas Oil (VGO) into lighter and more valuable middle distillates (kerosene and gas oil) or naphta cuts.

A two-step process is generally used in industrial hydrocracking units $[12,13,16]$. The hydrotreatment (HDT) reactor uses a more robust catalyst, while the second, hydrocracking (HCK) reactor generally uses a bi-functional zeolite catalyst. The HDT reactor essentially serves to remove heteroatoms from the VGO feed in order to satisfy product quality constraints. Some of the heteroatoms, such as organic nitrogen, act as poisons for the more delicate HCK catalyst. This step includes removal of nitrogen via hydrodenitrogenation (HDN), sulphur by hydrodesufurisation (HDS), or metals via hydrodemettalation (HDM) reactions [12,16].

The feed of the HDT reactor is far more complex due to the presence of nitrogen- and sulphur containing compounds, as well as a high content in polycyclic aromatic compounds. A far larger set of potential chemical reactions must therefore be taken into account then modelling this step. The hydrotreated feed of the HCK reactor is assumed to be essentially free of heteroatoms and thus composed exclusively of hydrocarbon molecules. Nevertheless this still amounts to a far larger number of species than in a chemical reactor operating with relatively pure feeds and limited numbers of potential reactions. The purpose of this work is to establish a single events model for the HCK reactor. This can be considered as a step on the way to develop a complete model, including heteroatoms. Only the second reactor in the two-step setup is therefore simulated. 
Hydrocracking experimental runs were performed in the IFPEN pilot plant. The HDT and HCK steps are performed separately, according to the scheme presented in Figure 1. This setup allows detailed analyses to be performed on the pre-treated feed [16]. The same feed can then be used in different HCK runs. It is important to note that the gasses produced in the first reactor are separated. Ammonia gas must therefore be added to the HCK reactor in order to simulate the effect of carryover of this gas that would occur in an industrial unit. A more detailed description of the HCK process used in this study can be found in $[3,16,17]$.

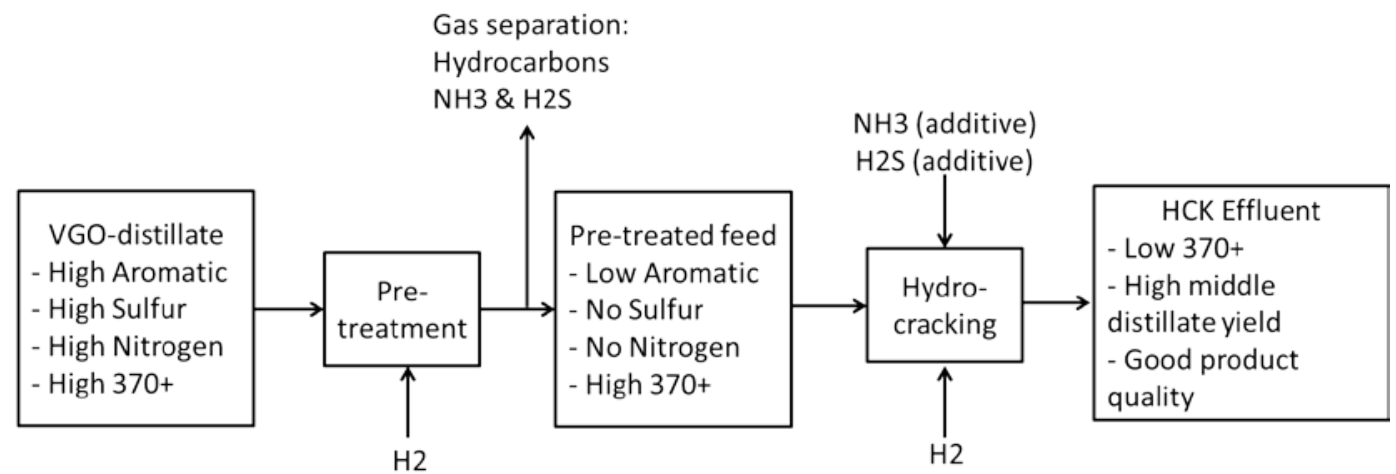

Figure 2 : Schematic representation of the two step hydrocracking process with intermediate storage/analysis of the pre-treated feed

HDN and HDS reactions produce ammonia and hydrogen-sulphide gas. These gases are carried over to the second reactor. In this study, the pre-treatment is performed separately from the HCK step. The gasses produced in the HDT reactor are removed from the feed of the HCK reactor. Aniline and dimehtyl di-sulphite additives are used to simulate the effect of NH3 and H2S gases. Ammonia has a notable inhibition effect on the acidic phase of the zeolite catalysts. The aromatics content is reduced by hydrogenation of the unsaturated bonds in aromatic rings. A small amount of hydrocracking equally happens in the HDT reactor. The second, HCK reactor performs the cracking of long hydrocarbon chains in order to maximize the yield of the more valuable light and/or middle distillates. 


\subsection{The Hydrocracking Catalysts}

Hydrocracking is a catalytic cracking process, which is performed at high temperatures (up to $400^{\circ} \mathrm{C}$ ) and at high hydrogen pressures (140 bar) on a bi-functional catalyst (i.e. including an acid and a metallic functionality) [14,18-20]. The elementary reactions occurring on the metallic and acid sites of the catalyst are shown in Figure 2.

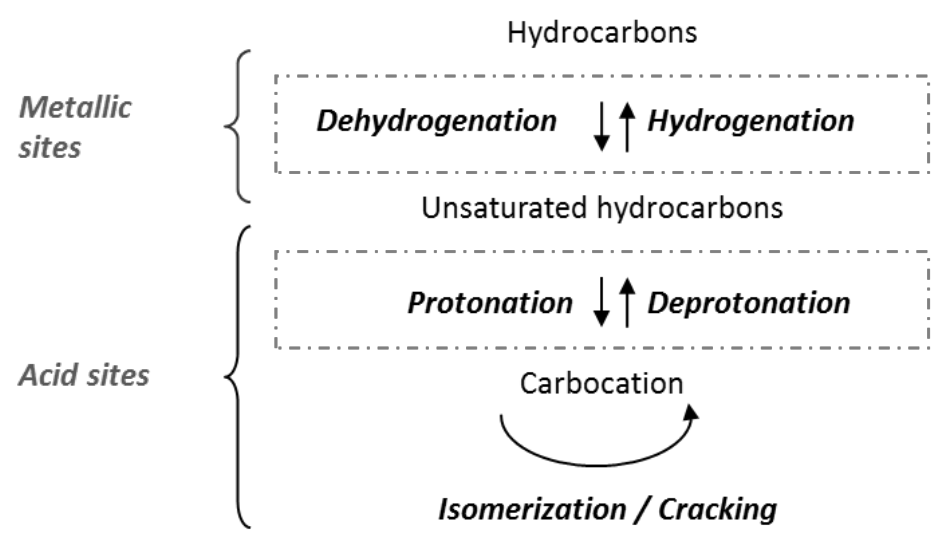

Figure 3: Schematic representation of hydrocracking reactions [10]

Hydrogenation of saturated hydrocarbons, producing unsaturated hydrocarbons occurs on the metallic site. The unsaturated species thus formed then undergo protonation to a carbocation on the acid sites. These very reactive carbocation can then undergo PCP (Protonated Cyclo-Propane) branching, methyl shift, or $\beta$-scission reactions [21]. Hydrogenation of unsaturated hydrocarbons present in the feed (i.e. aromatic rings) occur on the metallic sites of the bi-functional catalyst. A good review of the current understanding of the fundamental chemistry of hydrocracking on bi-functional catalysts is given by Weitkamp [19].

\subsection{Nitrogen Inhibition}

The presence of ammonia gas (NH3), which is formed by hydrogenation of nitrogen-containing aromatic compounds (HDN), have a known inhibition effect on the bi-functional catalysts. The NH3 
molecules adsorb on the acidic sites of the catalyst and thus inhibit the protonation step. This step, which generates the reactive intermediate [18], is often rate determining. Nitrogen content of the feeds of the pre-treatment reactor generally varies between 1000 - 3000 ppm, depending on geographic and geologic origin. The ammonia flowrate does not change along the second reactor, unless the HDN reaction in the first reactor is less than $100 \%$. In this work, it is assumed that nitrogen is completely removed from the feed in the pre-treatment step.

Any hydrocracking model to be applied to an industrial unit and feeds must take this inhibition effect into account. This effect is generally done by introducing a Langmuir-type or simple power-law inhibition term in the kinetic equations [12,16]. A Langmuir type expression (equation 1) is used in this work. The same inhibition parameter is applied to all kinetic rate expressions.

$$
I_{p p N H_{3}}=\frac{\alpha * p p N H_{3}}{\left(1+\alpha * p p N H_{3}\right)}
$$

Where : ppNH3 stands for partial pressure of NH3.

A single pre-treated feed, which is practically free of nitrogen is used in this study. The varying nitrogen content of the feed is therefore simulated by adding a known quantity of aniline. This additive rapidly breaks down into NH3 and CH4 gas. Methane gas formation and hydrogen consumption due to aniline breakdown has been removed from the overall mass balances.

\subsection{Hydrocracking Models}

Hydrocracking process modelling was extensively studied during the past decades. An extensive review of the existing models was done by Ancheyta et al. [11]. The authors distinguish the models in 4 classes. These are, in increasing order of complexity:

1) models based on wide distillation range fractions

2) models based on pseudo components 
3) model based on continuous mixtures or

4) micro kinetic models.

The overall behaviour, i.e. hydrocarbon conversion, yield structure, Simulated Distillation (SIMDIS), can be accurately predicted by relatively simple modelling approaches, such as the discrete [22-24],or the continuous lumping $[11,16,25,26,8,17]$ approaches. Such models are essential in order to optimize the yield and/or product quality of industrial hydrocracking units. However, these traditional approaches provide limited information regarding the chemical composition of the effluent or the cracking kinetics of the individual species. A well-defined microkinetic model, on the other hand, can help to gain a comprehensive understanding of the underlying chemical mechanisms. This is essential for the development of new and improved catalysts.

Unlike microkinetic models for chemical systems with a limited number of relatively pure components it is not feasible to define the complete reaction network for complex, petroleum-derived hydrocarbon mixtures. Computational algorithms have been developed to generate the extensive networks with can contain an order of $10^{5}$ to $10^{6}$ individual reactions. The single event micro kinetic modelling method was originally developed by Froment et al. [1,27-31]. The single events coefficients [3,5] are then calculated for each individual reaction, before a rigorous re-lumping is performed in order to reduce the size of the network without loss in information. Algorithms have been proposed for hydrocracking [27], reforming [32], isomerization [33], alkylation [7].

However, the original re-lumping method remains unfeasible for application to large networks, even with current computational capabilities $[10,34]$. An alternative method, based on a lateral chain decomposition was developed by Valery [3,6,35,2]. This method classifies molecules in terms of a) chemical family, b) number of carbon atoms, and c) branching degree.

Because of the complexity involved single events models have traditionally been applied only to light molecules [36,37]. More recently, these models have been applied to long-chained alkanes 
$[3,6,32,33,2]$. This work aims to further extend the methodology to include saturated and unsaturated cyclic components with up to 55 carbon atoms in order to be capable of simulating a real hydrotreated VGO feed. The typically contains, in terms of mass, 20 - $30 \%$ paraffins, 50 - $80 \%$ naphtenes, and 10 $-20 \%$ aromatics. The high concentration of cyclic shows that the extension to the single events model is indispensable for the simulation of such feeds.

Future extensions of this model should take heteroatoms (sulphur, nitrogen, oxygen) into account to simulate even more complex reactions mixtures, such as the feed of the HDT reactor or biomass derived feeds.

\section{Feed Reconstruction}

The precise chemical composition of the feed is required as input to a microkinetic model. This is, however, impossible to obtain for petroleum derived feeds [38,39]. A reconstruction of the feed needs therefore performed. The molecular composition, in terms of a number of chemical families and molecule size (i.e. carbon number), is determined such that the recombined feed characteristics correspond to measurable quantities[40]. Different reconstruction methods exist, depending on the nature of the petroleum cut to be analysed. The hydrotreated VGO feed used in this study was fractioned into three cuts (PI-150, 150-370, and $\left.370+^{\circ} \mathrm{C}\right)$. The most appropriate reconstruction algorithm was applied to each cut:

- Naphtha cut $\left(>150^{\circ} \mathrm{C}\right)$ : fully characterized by analytical mehtods

- Middle distillate cut $\left(150\right.$ - $\left.370^{\circ} \mathrm{C}\right)$ : statistical reconstruction based on GCxGC [41,42]

- Residue cut $\left(<370^{\circ} \mathrm{C}\right)$ entropy maximization method [43] 
The complete VGO feed was thus characterized in terms of 19 chemical families (shown in Figure 4). A detailed description and evaluation of the reconstruction algorithm will be the object of a future publication.

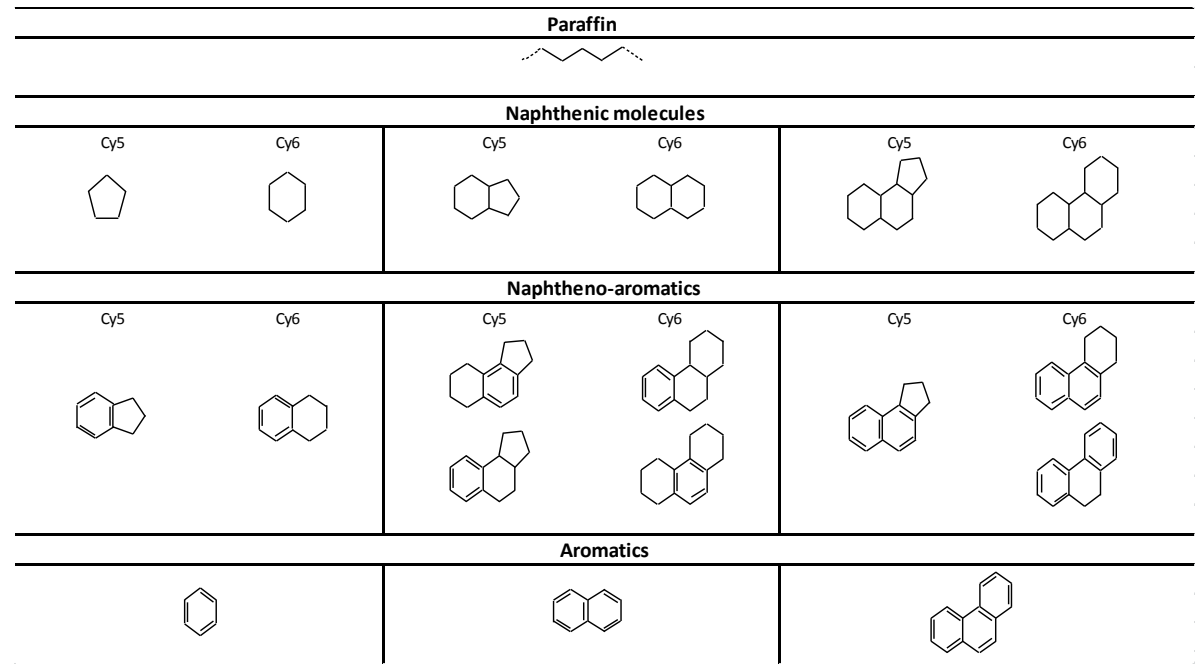

Figure 4 Library of chemical families

\section{The Single Events Microkinetic Model}

\subsection{Model Development}

Hydrocracking models previously developed by IFPEN considered only paraffinic molecules $[3,6,32,33,35,2]$. The basic concepts of the microkinetic model and reaction network generation are outlines in section 4.2. This section will focus on the extensions to the original model rather than provide the methodology in exhaustive detail. A complete description of the single events methodology, as applied to hydrocracking on bi-functional catalysts, as well as a review the theoretical back ground can be found in [3]. In this work, the existing model is extended to include naphthenic, aromatic and naphtheno-aromatic molecules.

The $\beta$-scission and PCP-isomerization reactions are present in the previous models. The reaction network and single events coefficient generation algorithms were extended to include reactions 
involving saturated and unsaturated cycles. This is described in section 4.3. The model used for hydrogenation of aromatic rings, which occurs on the metallic sites of the catalyst, is described in section 4.3.4.

\subsection{Single-event \& Lateral Chains methods}

A brief overview of the single events concept and the network generation by lateral chain decomposition is provided in this section. A more thorough description can be found in [3].

The intermediate steps of each. $\beta$-scission and PCP-branching reaction, i.e. hydrogenation/dehydrogenation, protonation/deprotonation, and carbenium ion formation (see Figure 2), are assumed to be at equilibrium [4]. Furthermore, the amount of olefins is assumed to be negligible with respect to the amount of saturated or aromatic species.

The 19 molecular families which were used to reconstruct the hydrotreated VGO fee (see section 3) were used as a basis for the extended reaction network. The method can be easily extended to include any number of carbon atoms and branching degree required. Hydrocarbons with up to three saturated and/or unsaturated cycles, and a maximum of 55 carbon atoms are considered in this work. Cycles are assumed to fused and a maximum of one cyclopentane is permitted per molecule. A single lateral chain, with a maximum of three methyl-type branches can be attached to the cyclic head. Each molecular species used in the model is thus characterized exclusively by:

a) Nature of cyclic head

- Number of cyclopentanes

- Number of cyclohexanes

- Number of aromatic cycles

- Position of cycles (for tri-cyclic naphtheno-aromatics)

b) Number of carbon atoms 
c) Number of methyl-type branches

The molecules within a single species are considered to be in equilibrium.

The single events concept is based on the number possible ways one species can be transformed into another compared to the total number of possible transformations via the same activated complex. The kinetic parameter for an elementary step can then be written as [9]:

$$
k=\frac{\sigma_{g l, r}}{\sigma_{g l, \neq}} \frac{k_{B} T}{h} \exp \left(\frac{\Delta \tilde{S}^{0, \neq}}{R}\right) \exp \left(\frac{\Delta H^{0, \neq}}{R T}\right)
$$

Where:

$$
\begin{array}{cl}
\mathrm{k} & \text { Kinetic coefficient }\left(\mathrm{s}^{-1}\right) \\
\Delta \tilde{S}^{0 \neq} & \text { Reaction Entropy }\left(\mathrm{J} \mathrm{mol}^{-1} \mathrm{~K}^{-1}\right) \\
\Delta \mathrm{H}^{0 \neq} & \text { Reaction enthalpy }\left(\mathrm{J} \mathrm{mol}^{-1}\right) \\
\mathrm{R} & \text { Gas constant }\left(8.314 \mathrm{Jmol}^{-1} \mathrm{~K}^{-1}\right) \\
\mathrm{T} & \text { Reaction temperature }(\mathrm{K}) \\
\mathrm{h} & \text { Planck constant }\left(6.626 \times 10^{-34} \mathrm{~m}^{2} \mathrm{~kg} \mathrm{~s}^{-1}\right) \\
\mathrm{k}_{\mathrm{B}} & \text { Boltzmann constant }\left(1.381 \times 10^{-23} \mathrm{~m}^{2} \mathrm{~kg} \mathrm{~K} \mathrm{~K}^{-1}\right) \\
\sigma_{g l, r} & \text { Global symmetry number of reactant } \\
\sigma_{g l, \neq} & \text { Global symmetry number of transition state }
\end{array}
$$

The energy terms in equation (2) are calculated using the Benson group contribution method [44]. The number of single events $\left(n_{e}\right)$, defined in equation (3), depends only on the symmetry of the intermediate and the product. The a-posteriori re-lumping method is described in [3].

$$
n_{e}=\frac{\sigma_{g l, r}}{\sigma_{g l, \neq}}
$$


The intrinsic kinetic parameter and activation energy, $\mathrm{k}_{0}$ \& Ea respectively, is considered common for each type of reaction (i.e. or $\beta$-scission and PCP-isomerization).

\subsection{Extension to Cyclic Species}

As detailed in section 2.1, current models only include linear alkanes. The $\beta$-scission and PCPisomerization reactions of the lateral chains, attached to the cyclic centres, are treated according to the original method. These reactions are referred to as acyclic reactions. The additional types of reactions, which involve the cyclic heads are detailed in the following.

\subsubsection{Exo-cyclic $\beta$-scission \& PCP-isomerization}

The carbenium ion can be placed on the cycle itself, rather than the lateral chain, when an unsaturated bond on a cycle is protonated on an acid site (see Figure 3). In the case of cyclopentanes and cyclohexanes, the saturated bond must first be dehydrogenized on a metallic site. These intermediates can the cracking of the lateral chain in the vicinity of the ring, or the increase/decrease of branching degree due to the PCP-isomerization mechanism. The intrinsic parameter for exocyclic reactions of naphthenes are considered the same as for alkanes, while exocyclic reactions involving aromatic rings have a different set of kinetic parameters ( $\left.\mathrm{k}_{0} \& \mathrm{Ea}\right)$.

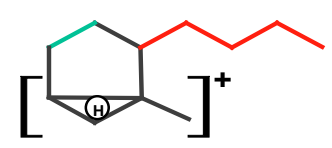

Figure 5 Example of cyclic carbenium ion intermediate

\subsubsection{Endo-cyclic PCP-isomerization}

The PCP-isomerization mechanism on a carbenium ion on a saturated cycle can cause a ring contraction/expansion between cycles of 5 or 6 carbon atoms. In the case of a ring expansion, a methyl 
group must be present of the cyclopentane. This methyl group is then moved into the ring, forming a cyclohexane. The inverse is true for ring contractions.

\subsubsection{Endo-cyclic $\beta$-scission}

Exo- and acyclic $\beta$-scission can only reduce the total mass of naphthenes in the effluent by reducing the total number of carbon atoms in the cyclic molecules. The overall number of saturated cyclic and straight chain carbon atoms, however, remains the same. The $\beta$-scission reaction of a carbenium ion located on a saturated cycle can lead to the opening of the ring on which it is located. This mechanism, denoted endo-cyclic $\beta$-scission, is responsible for the reduction in numbers of cycles in the reaction mixture.

\subsubsection{Hydrogenation of Aromatic Cycles}

Hydrogenation of aromatic hydrocarbons is an important function of hydrocracking units. Correct estimation of aromatic content of the effluent and the different standard cuts is a critical requirement for HCK models. A single events microkinetic model to be applied to an industrially relevant HCP process must therefore include these hydrogenation reactions.

The hydrotreatment of heavy vacuum residues was studies by [45], who applied Quantitative Structure /Reactivity Correlations (QS/RC) [46] to model the hydrogenation of light cycle oils and VGO reside. This model is used here to estimate the hydrogenation rates of molecular species with respect to number of cycles. The rate of the forward/backward reactions is given below.

$$
\begin{gathered}
R_{\text {hydro }}=k_{0} k_{s r} k_{a d s} p p H_{2}^{n_{H 2}} \\
R_{\text {deshydro }}=k_{0} \frac{k_{s r} k_{a d s}}{k_{e q}}
\end{gathered}
$$

Where: 


$\begin{array}{cl}\mathrm{R} & \text { Rate of hydrogenation / deshydrogenation }\left(\mathrm{s}^{-1}\right) \\ \mathrm{k}_{\mathrm{sr}} & \text { Kinetic constant (equation 6) } \\ \mathrm{k}_{\mathrm{ads}} & \text { Adsorption constant (equation 7) } \\ \mathrm{k}_{\mathrm{eq}} & \text { Equilibrium constant (equation 8) } \\ \mathrm{ppH}_{2} & \text { Hydrogen partial pressure (bar) } \\ \mathrm{n}_{\mathrm{H} 2} & \text { Number of } \mathrm{H}_{2} \text { molecules consumed } \\ \mathrm{k}_{0} & \text { Kinetic parameter (to be identified) }\end{array}$

With the QS/RC relations taken from Pereira de Oliveira [45]:

$$
\begin{aligned}
& \ln \left(k_{s r}\right)=-7.06 n_{H 2}^{1 / 2}-0.13\left|\Delta H_{R}^{0}\right| \\
& \ln \left(k_{a d s}\right)=1.15+0.616 N_{A R}+0.330 N_{S A T} \\
& \ln \left(k_{e q}\right)=2.952-13.215 n_{H 2}+0.625\left|\Delta H_{R}^{0}\right|-0.784 N_{S A T}
\end{aligned}
$$

Where:

$\Delta H_{R}^{0} \quad$ Standard heat of reaction $\left(\mathrm{kcal} \mathrm{mol}^{-1}\right)$

$\mathrm{N}_{\mathrm{SAT}} \quad$ Number of saturated cycles

$\mathrm{N}_{\mathrm{AR}} \quad$ Number of aromatic cycles

The standard heat of reaction is $-206.2 \mathrm{~kJ} / \mathrm{mol}$ for hydrogenation of benzene (C6H6) to cyclohexane (C6H12) and $-124.0 \mathrm{~kJ} / \mathrm{mol}$ for hydrogenation of naphthalene (C10H8) to tetraline (C10H12). Furthermore, 3 molecules of $\mathrm{H}_{2}$ are required for the former, while only two moles of $\mathrm{H}_{2}$ are required for the latter. Equations (6) - (8) therefore imply that hydrogenation of compounds with more than one (condensed) aromatic rings is much faster than hydrogenation of a single aromatic ring. 
It is important to note that this model does not account for the effect of the lateral hydrocarbon chain and/or the number of methyl groups on the aromatic ring. No model allowing this level of detail to be taken into account exists to the authors' knowledge.

\section{Materials \& Methods}

\subsection{Experimental Set up}

A hydrotreated VGO distillate was used as feedstock in this study. Hydrocracking experiments were performed in a IFP Energies Nouvelles plant, located in Solaize, France. The reactors were loaded with a commercial catalyst. Temperature along the reactors was controlled to ensure iso-thermal operating conditions. The feed of the hydrocracking reactor in a two-reactor set-up (see Figure 1) carries over the gasses produced in the hydrotreatment step. These gasses are not present with the feedstock used in this study. The $\mathrm{NH}_{3}$ gas produced from the HDN reaction has a notable inhibition effect on the bi-functional catalyst (see sections 2.2.1 and 2.1). An aniline additive, which breaks up rapidly into $\mathrm{NH}_{3}$ gas, was used in order to simulate this effect in the experimental runs used in this study. The nitrogen content of a feed resulting in the equivalent $\mathrm{NH}_{3}$ production in the hydrotreatment step is given as $\mathrm{N}_{\mathrm{R} 1}$. The breakdown products of aniline additive are taken into account in the yield structure calculations.

All experiments were run at a pressure of 140 bar. The operating conditions were chosen to cover a very large range of conversion (20 - 90\%). Hydrocarbon conversion was controlled by temperature and by the ratio of aniline additive (NR1) to the relative hydrogen flowrate (H2/HC). The latter is equivalent to the NH3 partial pressure. Three reaction temperatures $\left(\mathrm{T}=370,380\right.$, and $\left.385^{\circ} \mathrm{C}\right)$, and two different contact times (lhsv $=1.5$ and $2.0 \mathrm{~h}^{-1}$ ) were tested. A summary of the 8 mass balances is given in Figure 4. 
Mass balances were taken at stable operating conditions over a period of around 12 hours. A total of 8 mass balances were taken for this study. Yield structure was determined in term of standard cuts (150, 250, and $370^{\circ} \mathrm{C}$ ), as well as SIMDIS for each mass balance. The detailed molecular composition of 8 mass balances was measured by GCxGC $[38,39,47]$, as detailed in part 1 . The mass distribution of Paraffinic (P), Naphtenic (N), and Aromatic (A) species in the residue $\left(>370^{\circ} \mathrm{C}\right)$ and middle distillate $\left(150-370^{\circ} \mathrm{C}\right)$ cuts was measured using mass spectroscopy.

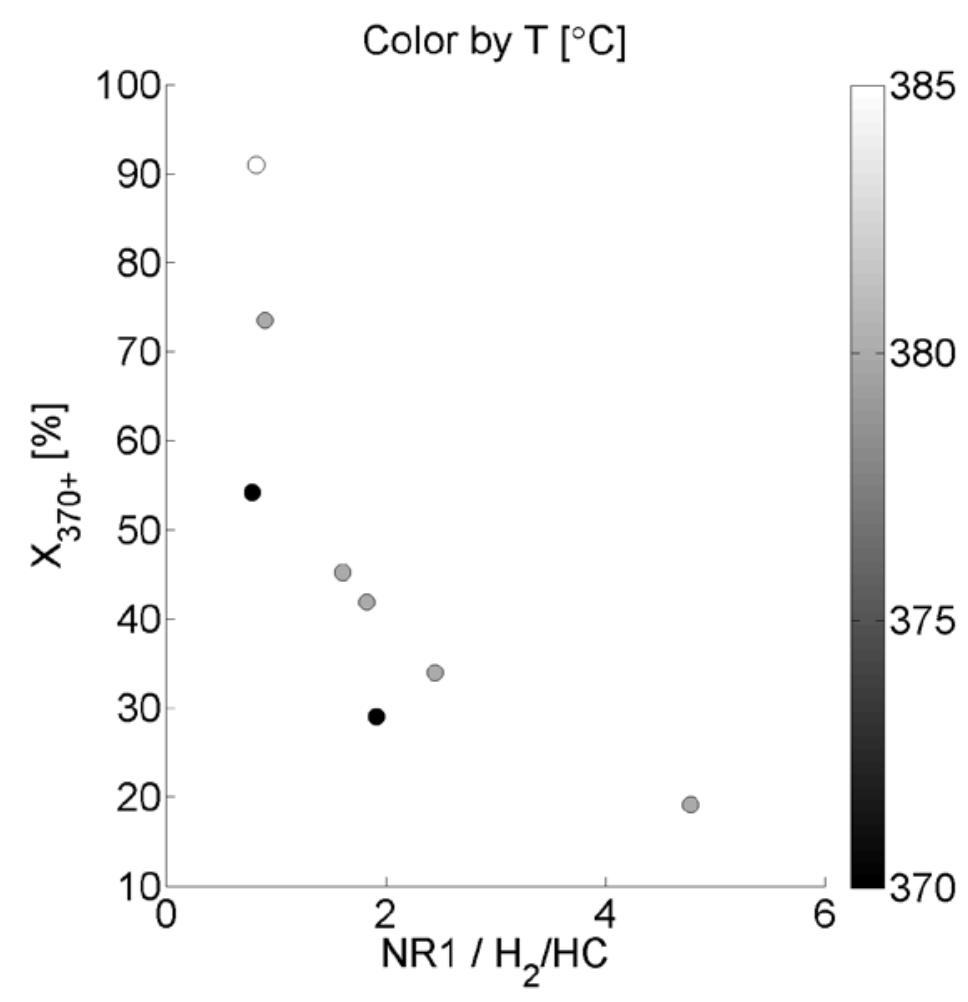

Figure 6 Summary of operating conditions for mass balances used in this study

The molecular reconstruction of the VGO feestock, presented in section 3, was used as input for the simulation presented in the following section. This reconstruction was shown to be in good agreement with analytical measurements. The molecular reconstruction of the effluents is not used in this part, because it was found to be less reliable, and because full analytical data is not available for all mass balances. Identification of the kinetic parameters, and validation of the simulation results is therefore based directly on the measurements. 


\subsection{High Performance Computing}

The single events model is encoded as a set of 3,319 ODEs, corresponding to the 19 families (see Figure 4) with up to 55 carbon atoms and a maximum of 3 methyl-type branches, as well as one equation for $\mathrm{H}_{2}$. The reaction network contains a total of 110,852 reactions. The model is implemented in a Fortran (F90) application, coded in object oriented style. The well-known DD2BDF (lsode) algorithm is used to solve the set of equations. Resolution of a single mass balance, using a single Intel Xeon CPU (2.53 MHz) on a desktop workstation takes around 2 minutes of computational time. The individual mass balances are solved sequentially. While running a single simulation is clearly feasible, performing parameter optimization, which requires 100s or 1000s of simulations of all mass balances in the database, will quickly become prohibitive on such a setup. The computational cost becomes more critical when considering the much larger databases typically used to identify kinetic models for industrial applications (e.g. 52 in [17] and 44 in [16]).

The code was therefore parallelized using the Message Passing Interface (MPI) provided by Intel $^{1}$, in order to execute the code on the High Performance Computing (HPC) cluster at IFPEN. The equations for each individual mass balances are solved by a separate core (i.e. processor). This implies that the computational time to simulate the complete database is limited to the computational time required to solve a single mass balance. The number of cores required increases with the number of mass balances to be simulated.

A different approach would be the distribution of the calculation of the 110,852 reactions across any number of processors. This would correspond to a speedup of the computational time required to simulate a single mass balance. This option is not used here, since this remains relatively moderate for the model presented here. Nevertheless, for 8 mass balances, a speedup of a factor of 8 is achieved. A parameter optimization requiring 600 function evaluations, which would take an entire week on a desktop workstation, is performed in less than 12 hours on the supercomputer. N.B. this speedup is

\footnotetext{
${ }^{1}$ https://software.intel.com/en-us/intel-mpi-library
} 
increased by the fact that individual processors of the HPC cluster are more powerful than the ones of the desktop workstation.

The size of the reaction network increases exponentially with the number of molecular species considered. This is the case when extending the HCK model is to include heteroatoms or increased molecule size or branching degree. The computational time for the simulation of a single mass balance on a desktop workstation can then become unfeasible. Parallelization with the aim of speeding up this simulation time can make using such a model possible.

\section{Simulation results}

\subsection{Kinetic Parameter Identification}

The kinetic parameters were identified using the SQA non-linear least-squares optimization algorithm [48]. This derivative-less trust region algorithm uses a response surface, constructed based on $2 * \mathrm{NP}+1$ interpolation points, to find a local minimum in the objective function. This algorithm was found to give better faster convergence than gradient based algorithms. A comparison of the objective function with the DN2FB algorithm provided in the PORT library is given in Figure 7. 


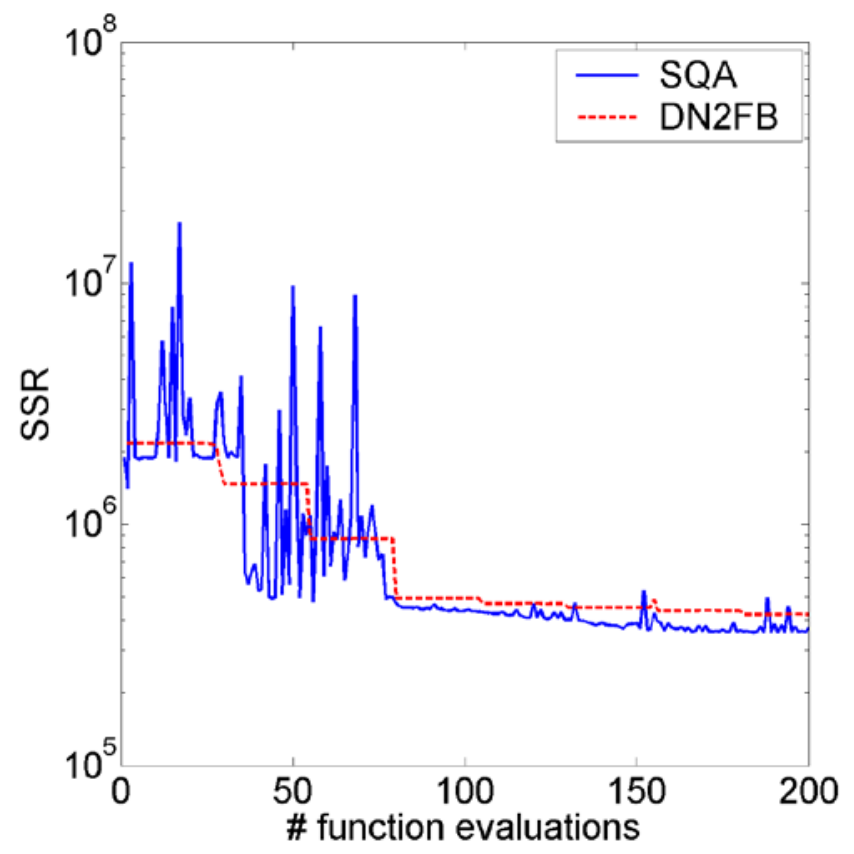

Figure 7 Comparison between optimization algorithms

The objective function was found to be highly non-convex, with a number of local minima. Optimizations were performed for 100 initial points, constructed by Latin Hypercube Sampling Design of Experiment [49]. The best optimum was retained.

The objective function was constructed using easily measurable macroscopic quantities, such as the SIMulated DIStillation (SIMDIS), yield structure by fractional distillation, or mass spectroscopy results. These measurements are more easily available in an industrial setting than more complex methods, such as GCxGC $[39,47]$. Correct prediction of these macroscopic quantities is a strict requirement for any hydrocracking model to be useful in a real industrial context.

An objective function taking the following into account, was constructed:

- $\quad$ Residue $\left(>370^{\circ} \mathrm{C}\right.$ cut $)$ conversion $\left(\mathrm{X}_{370^{+}}\right)$

- yield structure in terms of standard cuts $\left(150,250,370^{\circ} \mathrm{C}\right)$

- $\quad$ P-N-A composition of the middle distillate and residue cuts (by mass spectroscopy)

- Total yield (feed yield + hydrogen consumption) 
- $\quad$ Total yield (total yield - hydrocarbon gas production)

A total of 17 kinetic parameters, including 7 pre-factors $\left(k_{0}\right)$ and activation energies $\left(E_{a}\right), 2$ parameters for protonation, and one ppNH3 inhibition term $(\alpha)$, were thus identified. The simulation results, obtained using the identified kinetic parameters, are presented in the remainder of this section.

The simulated macroscopic effluent properties, i.e. yield structure and paraffin - naphtha - aromatics distribution, of the effluent are compared to measured values in sections 6.2 and 6.3. This serves to validate the simulation results. The characteristics of the model is explored in more detail in section 6.4. In this section, the evolution of the different groups of molecular species along the reactor are presented and analyzed.

\subsection{Residue Conversion \& Yield Structure}

The simulation results for the yield structure, in terms of three standard cuts: naphta ( $\mathrm{TBP}<150^{\circ} \mathrm{C}$ ), middle distillate $\left(\mathrm{TBP}=150-370^{\circ} \mathrm{C}\right)$, and residue $\left(\mathrm{TBP}>370^{\circ} \mathrm{C}\right)$ are shown in Figure 9. Gas yield (i.e. hydrocarbons with up to 4 carbon atoms) are also shown. The parity lines for absolute errors of \pm 5 $\%_{\text {(w/w) }}$ and $\pm 10 \%_{\text {(w/w) }}$ are provided. 


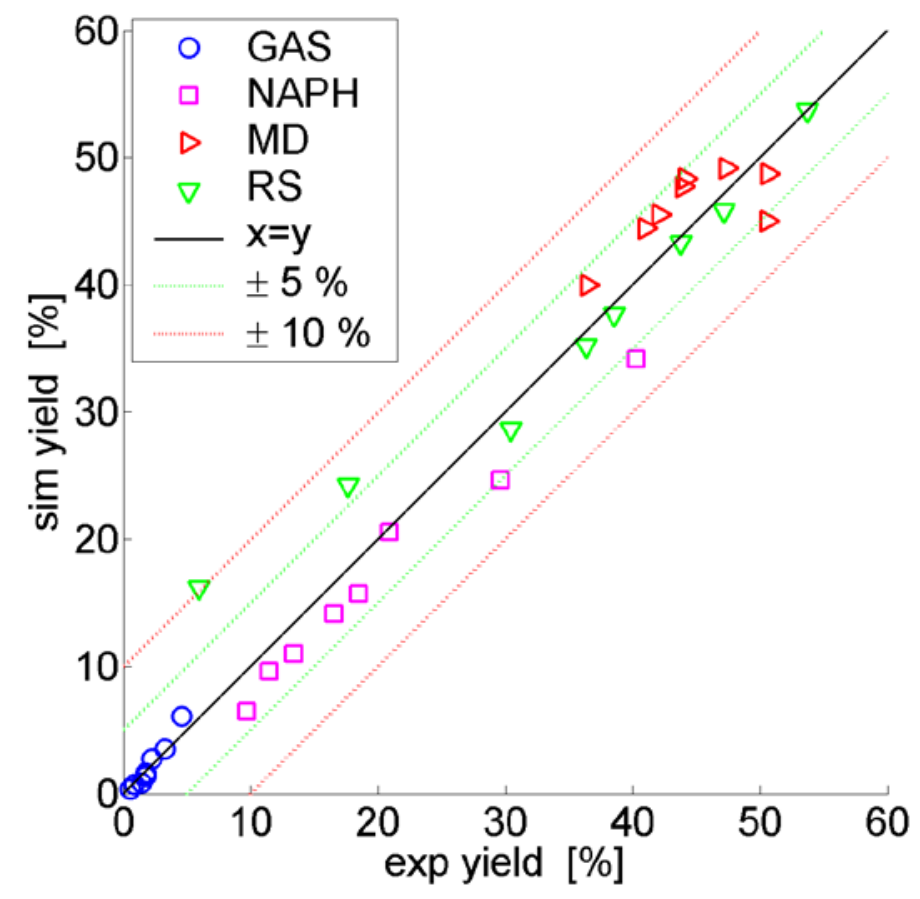

Figure 8 Comparison of experimental and simulation results for yield structure in terms of three standard cuts ( $\mathrm{NAPH}<150^{\circ} \mathrm{C}, \mathrm{MD} 150-370^{\circ} \mathrm{C}, \mathrm{RS}>370^{\circ} \mathrm{C}$ ), and hydrocarbon gas $(\mathrm{C} 1-\mathrm{C} 4)$

The single events model presented here provides very good simulation results for the conversion of VGO distillate The good agreement between simulated and measured residue $\left(>370^{\circ} \mathrm{C}\right.$ cut) yield shows that the model is capable of providing a correct estimation of residue conversion. This is one of the essential requirements of a hydrocracking model. The yield of the lighter middle distillate and naphtha cuts, which are the products of the process, are also very well predicted.

The simulations allow the macroscopic reaction kinetics to be studies in further detail. The evolution of the yield structure along the reactor, for a single mass balance at $385^{\circ} \mathrm{C}$ with a VVH of 1 are shown in Figure 8. The residue cut, which initially makes up about $65 \%$ of the feed can be seen to decrease. The rate is at first at an almost linear rate, before cracking begins to level off. This suggests that the different species crack at different rates. Once the residue cut has been reduced to about $15 \%$, all the easily crackable species have been eliminated and only the more refractory components remain. 


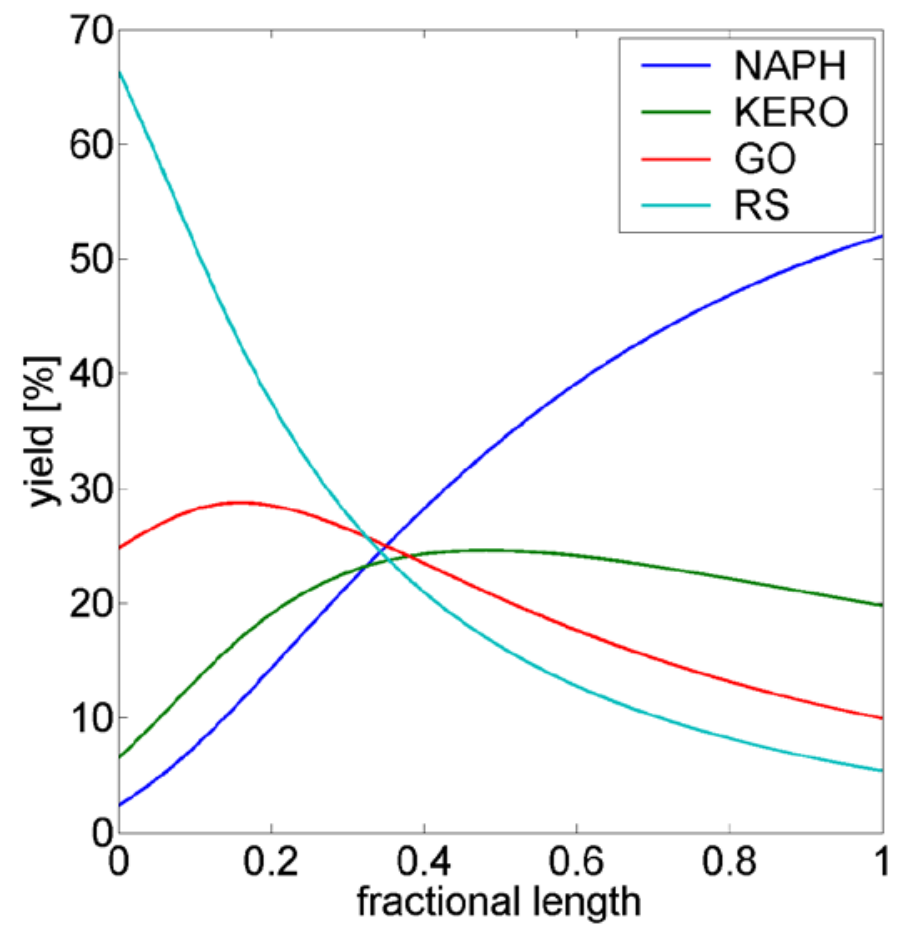

Figure 9 Evolution of the yield for the standard cuts along the reactor (NAPH $<150^{\circ} \mathrm{C}$, KERO $\left.150-250^{\circ} \mathrm{C}, \mathrm{GO} 150-250^{\circ} \mathrm{C}, \mathrm{RS}>370^{\circ} \mathrm{C}\right)$

The lighter cuts are produced from cracking of heavier molecules. The gasoil cut is yield is first increasing due to the cracking of heavier hydrocarbons. Once residue yield is decreased below $30 \%$, the gasoil yield begins to decrease. This is because the residue becomes depleted, decreasing the production of molecules with a TBP in the $150-250^{\circ} \mathrm{C}$ range. The hydrocarbons in the gasoil cut, however, continue to be eliminated by cracking into the kerosene and naphta cuts. The kerosene cut follows a similar trend; however the reaction is not continued far enough for a decrease in kerosene yield to be observed. The naphta cut, which is composed of very light molecules (TBP $<150^{\circ} \mathrm{C}$ ) is observed to steadily increase throughout the reaction.

\subsection{Distribution of Paraffinic -Naphthenic - Aromatic Compounds}


The mass spectroscopy measurements, which allows the distinction of paraffinic, napthenic, and aromatic components in the middle distillate and residue cuts are compared to simulation results in Figure 9.
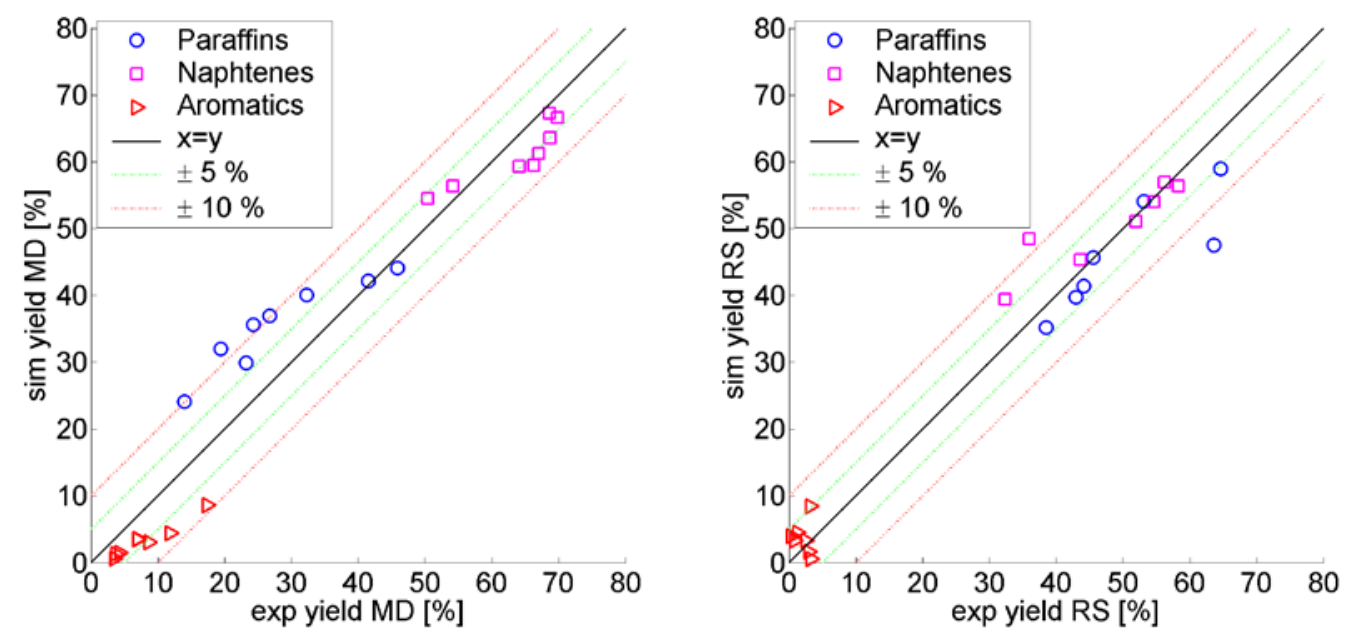

Figure 10 Comparison between measured (mass spectroscopy) and experimental distribution of paraffinic, naphthenic, and aromatic compounds in the middle distillate (left) and residue (right) cuts

The results, together with the very good prediction of the yield structure shows that the single events model presented in this work is capable of correctly predicting the macroscopic properties of hydrocracking effluents. This further underlines the validity of the model simulations.

The evolution of the PNA distribution along the reactor for a single mass balance with at $\mathrm{T}=385^{\circ} \mathrm{C}$ with a VVH of 2 is shown in Figure 12. 


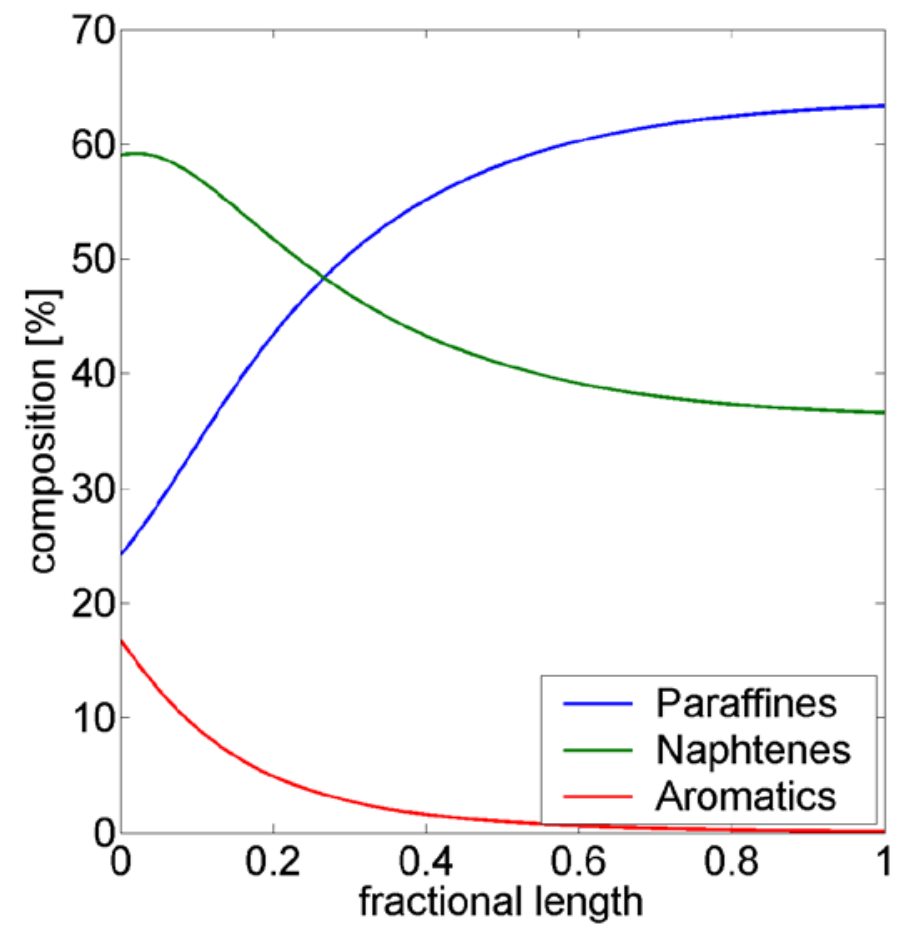

Figure 11 Evolution of Paraffin/Naphthene/Aromatics distribution along the hydrocracking reactor

This figure shows that the naphthene and aromatic molecules in the feed are rapidly converted into paraffins. This can happen though two distinct mechanisms. The cracking of lateral chains attached to a (poly-)cylic head, or the opening of saturated cycles via endo-cyclic $\beta$-scission. Aromatic rings are hydrogenated to naphthenes. A more detailed analysis of the evolution of individual components is given in the next section.

\subsection{Reaction Kinetics}

Much simpler models, (i.e. continuous lumping) are capable of simulating the yield structure as well as the single events model presented here [16], while requiring much less computational, analytical, and theoretical effort. They can also provide some coarse information of the effluent composition, such as the one shown in sections 6.2 and 6.3. They lack, however the full detail of the fundamental 
chemistry which make the microkinetic modeling approach so attractive. This detail is presented in this section.

Figure 11 shows the distribution of different classes of molecules with respect to number of carbon atoms at four different conversion for a simulation at $\mathrm{T}=385^{\circ} \mathrm{C}$. The initial 19 families have been lumped into the broad structural classes: normal- and iso-paraffins, naphtenes, aromatics, and naphtheno-aromatics (i.e. species composed of a combination of saturated and unsaturated cycles). The figure with conversion of $\mathrm{X}_{370^{+}}=0 \%$ corresponds to the feed composition.
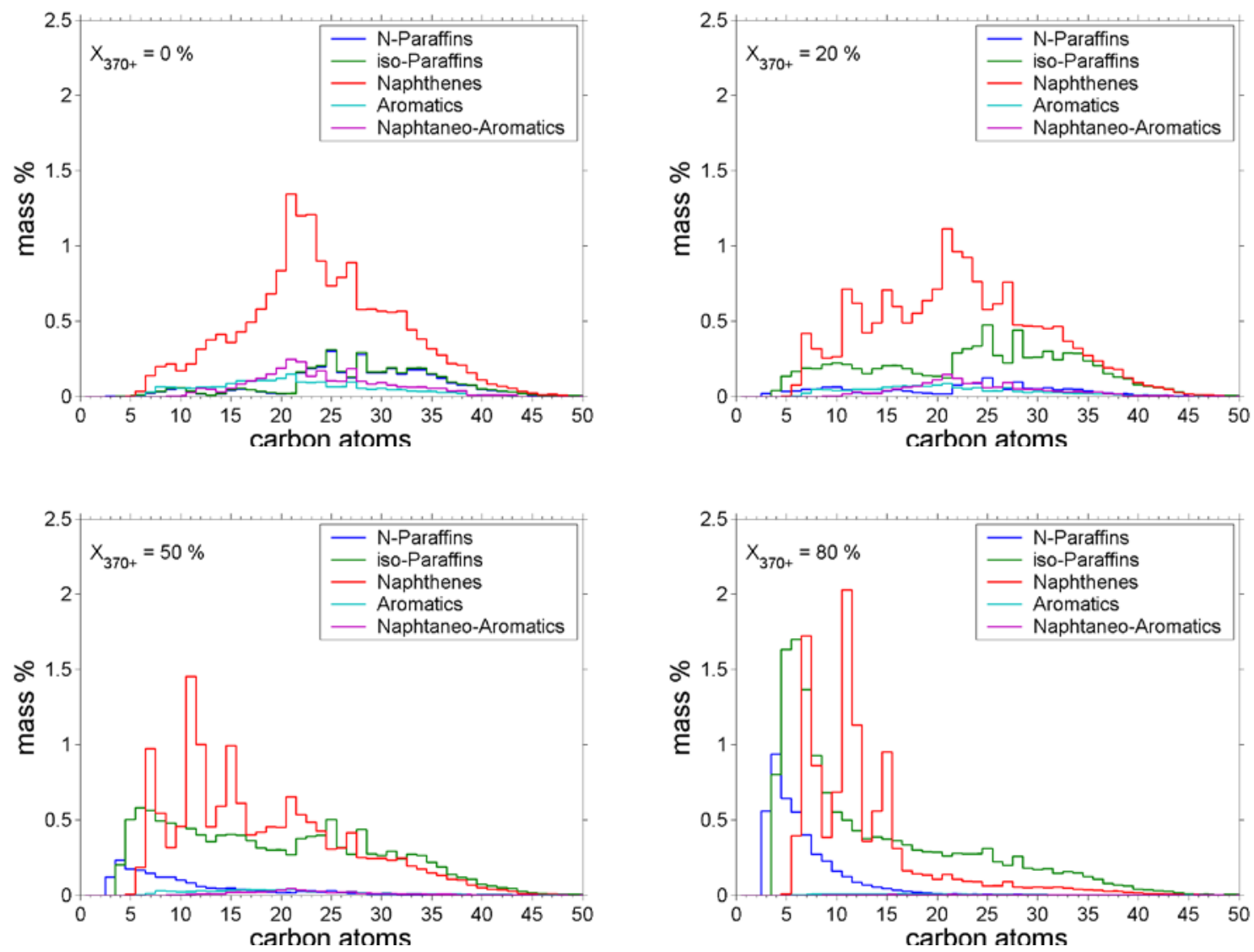

Figure 12 Simulated distribution of chemical species with carbon number at different levels of residue conversion $\left(\mathrm{X}_{370^{+}}\right)$

\subsubsection{Evolution of normal- and iso-parrafins}


The evolution of the composition of normal- and iso-paraffins along the reactor is shown in Figure 12. This shows that normal- and iso-paraffins are initially equally distributed (this is imposed as an assumption in the model). Normal paraffins are then rapidly isomerized into iso-paraffins (via PCP isomerization). The normal paraffin content proceeds to increase again, after reaching a minimum of around 5\%.

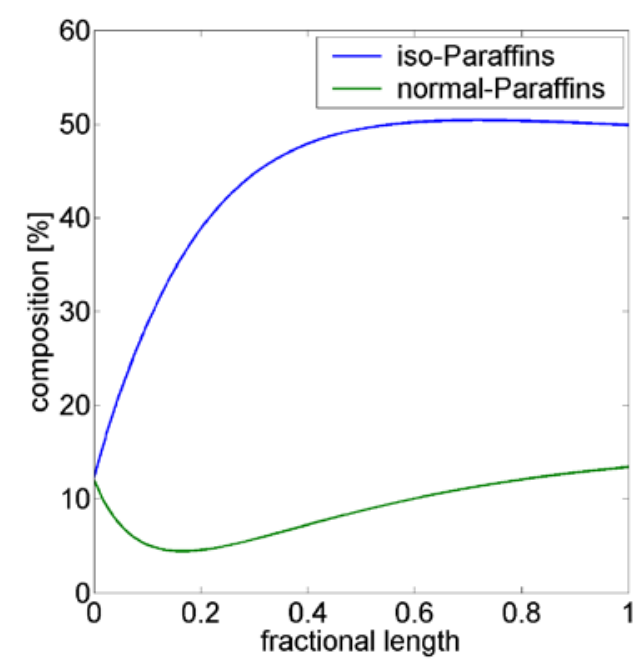

Figure 13 Evolution of iso- and normal-paraffins along the hydrocracking reactor

This behavior can be explained by considering the full distributions shown in Figure 13. The distributions at 50 and $80 \%$ conversion show that the normal paraffins for chains with more than 15 carbon atoms are almost entirely transformed into iso-paraffins. Normal paraffins are, however, present for smaller alkane chains. The longer chained molecules have a much higher number possible isomers than the smaller chained ones. This implies a higher number of single events which leads to a higher rate of PCP isomerization.

\subsubsection{Evolution of Naphthenes}

The distribution of naphthenic molecules shown in Figure 11 lump mono-, di-, and tri-cyclic molecules (see Figure 1). More detail, including number of cycles, is given in Figure 13. 


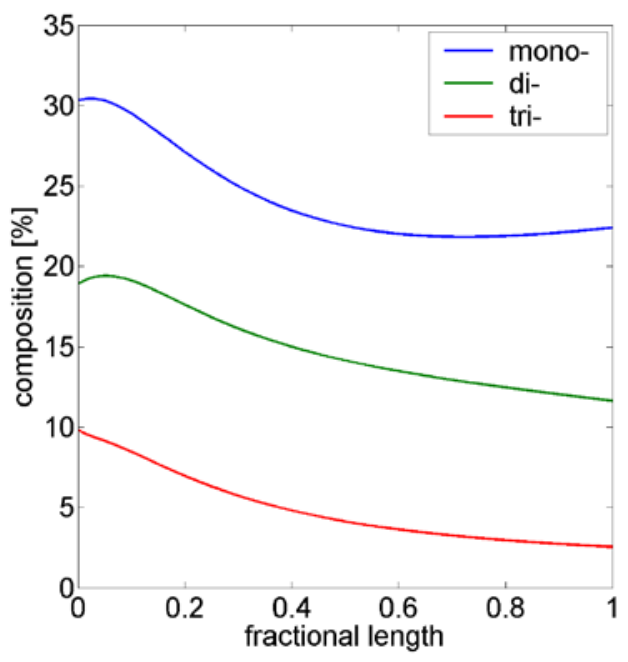

Figure 14 Evolution of saturated cyclic species (naphtenes) along the hydrocracking reactor

The feed contains roughly twice as many di- and three times as many mono- than tri-cyclic naphthenes (by mass). Decrease in mass content of cyclic species is due to two phenomena. Ring opening causes a reduction in the number of cycles at equal molecular mass (+ one $\mathrm{H} 2$ molecule being added in endocyclic beta scission). Cracking of lateral chains causes a reduction of molecular mass for an unchanged number of cycles.

The contents of tri- cyclic molecules is reduced from $10 \%$ to below 5\%. Di-cyclic first increases by a $2-3 \%$, before decreasing to around $12 \%$. Mono-cyclic species first increase by around $1 \%$ before rapidly leveling off around 23\%. In fact, the mass fraction of mono-cyclic naphtenes is seen to rise slightly towards the end of the reaction.

These observations, together with the results presented in the previous section suggests that ring opening reactions play a minor role and the size reduction is entirely due to cracking of lateral chains. The three peaks seen in Figure 11 correspond to naphthenes with 1, 2 and 3 cycles (i.e. 6, 10, and 14 carbon atoms) with one or two methyl groups. These species will not further reduce in size because the lateral chains are too small to be removed and ring opening reactions do not happen. The small 
increase in mono- and di-cyclic species is due to a small number of endo cyclic beta scission reactions occur rapidly on polycyclic compound.

\subsubsection{Evolution of aromatics \& naphtheno-aromatics}

Full details of the evolution of the content of aromatic and naphtheno-aromatic species is shown below in Figure 13. This figure makes the distinction between mono-, di- and tri-aromatic compounds, and naphtheno aromatic with one saturated and one unsaturated cycle (naph-aro), one saturated and two unsaturated cycles (naph-di-aro), and two saturated and one unsaturated cycles (di-naph-aro).

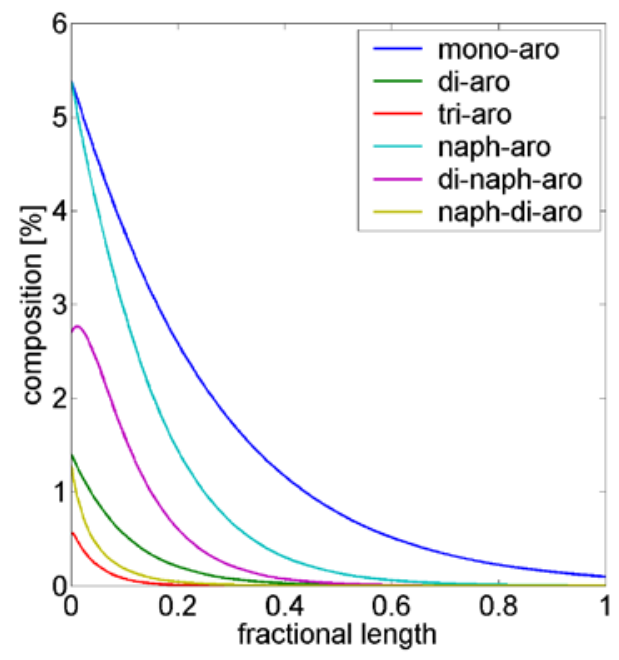

Figure 15 Evolution aromatic and naphtheno-aromatic species along the hydrocracking reactor

The content of all species containing aromatic rings is decreasing rapidly, tending to zero. This suggests that hydrogenation of aromatic rings is relatively fast, in addition to breaking of lateral chains. Mono-cyclic aromatics, however, decrease much slower than poly-cyclic compounds. This suggests that hydrogenation of a single aromatic ring is much slower than hydrogenation of multiple condensed rings. 


\section{Conclusions}

The single events microkinetic model, which has previously been applied only to long chained alkanes has been extended to include cyclic species. This is necessary because of the high content of cyclic species in the hydrotreated VGO feed (more than $70 \%_{(w / w)}$ see section 2.4 ). This model was then successfully applied to simulate hydrocracking of a real hydrotreaded VGO feed. The molecular reconstruction, presented in part I of this series, has been used as the basis for model development and to simulate the feed of the hydrocracking reactor.

Kinetic parameters of the single events model were identified using experimental data at industrial conditions from the IFPEN pilot plant. It was shown that the model is capable of correctly simulating macroscopic product characteristics. The yield structure and residue conversion is correctly predicted. The total paraffin/naphthene/aromatics distribution of the middle distillate and residue cuts are also well predicted. This shows that the model is valid for simulating hydrocracking of the given feed and the simulation results can be used to draw conclusions about the fundamental chemistry of the process.

Performing computations on the IFPEN HPC cluster allowed parameter identification with a number of initial points to be performed.

\section{References}

[1] Baltanas MA, Van Raemdonck KK, Froment GF, Mohedas SR. Fundamental kinetic modeling of hydroisomerization and hydrocracking on noble metal-loaded faujasites. 1. Rate parameters for hydroisomerization. Ind Eng Chem Res 1989;28:899-910. doi:10.1021/ie00091a004.

[2] Mitsios M, Guillaume D, Galtier P, Schweich D. Single-Event Microkinetic Model for LongChain Paraffin Hydrocracking and Hydroisomerization on an Amorphous Pt/SiO $2 \cdot \mathrm{Al} 2 \mathrm{O} 3$ Catalyst. Ind Eng Chem Res 2009;48:3284-92. doi:10.1021/ie800974q.

[3] Guillaume D, Valéry E, Verstraete JJ, Surla K, Galtier P, Schweich D. Single Event Kinetic Modelling without Explicit Generation of Large Networks: Application to Hydrocracking of Long Paraffins. Oil Gas Sci Technol - Rev d'IFP Energies Nouv 2011;66:399-422. doi:10.2516/ogst/2011118. 
[4] Schweitzer J-M, Galtier P, Schweich D. A single events kinetic model for the hydrocracking of paraffins in a three-phase reactor. Chem Eng Sci 1999;54:2441-52. doi:10.1016/S00092509(99)00006-8.

[5] Froment GF. Single Event Kinetic Modelling of Complex Catalytic Processes. Catal Rev 2005;47:83-124.

[6] Valéry E, Guillaume D, Surla K, Galtier P, Verstraete J, Schweich D. Kinetic Modeling of Acid Catalyzed Hydrocracking of Heavy Molecules: Application to Squalane. Ind Eng Chem Res 2007;46:4755-63. doi:10.1021/ie061559w.

[7] Martens G, Froment GF. Kinetic Modeling of Paraffins Hydrocracking based upon Elementary Steps and the Single Event Concept. Stud Surf Sci Catal 1999;122:333-40.

[8] Laxmi Narasimhan CS, Thybaut JW, Marin GB, Denayer JF, Baron GV, Martens J a., et al. Relumped single-event microkinetic model for alkane hydrocracking on shape-selective catalysts: catalysis on ZSM-22 pore mouths, bridge acid sites and micropores. Chem Eng Sci 2004;59:4765-72. doi:10.1016/j.ces.2004.07.093.

[9] Lozano-Blanco G, Surla K, Thybaut JW, Marin GB. Extension of the Single-Event Methodology to Metal Catalysis: Application to Fischer-Tropsch Synthesis. Oil Gas Sci Technol - Rev d’IFP Energies Nouv 2010;66:423-35. doi:10.2516/ogst/2009075.

[10] Kumar H, Froment GF. A Generalized Mechanistic Kinetic Model for the Hydroisomerization and Hydrocracking of Long-Chain Paraffins. Ind Eng Chem Res 2007;46:4075-90. doi:10.1021/ie060957w.

[11] Ancheyta J, Sánchez S, Rodríguez M a. Kinetic modeling of hydrocracking of heavy oil fractions: A review. Catal Today 2005;109:76-92. doi:10.1016/j.cattod.2005.08.015.

[12] Rana MS, Sámano V, Ancheyta J, Diaz J a. I. A review of recent advances on process technologies for upgrading of heavy oils and residua. Fuel 2007;86:1216-31. doi:10.1016/j.fuel.2006.08.004.

[13] Choudhary N, Saraf DN. Hydrocracking: A Review. Ind Eng Chem Prod Res Dev 1975;14:7483. doi:10.1021/i360054a002.

[14] Ward JW. Hydrocracking processes and catalysts. Fuel Process Technol 1993;35:55-85.

[15] Mohr SH, Wang J, Ellem G, Ward J, Giurco D. Projection of world fossil fuels by country. Fuel 2015;141:120-35. doi:10.1016/j.fuel.2014.10.030.

[16] Becker PJ, Celse B, Guillaume D, Dulot H, Costa V. Hydrotreatment modeling for a variety of VGO feedstocks: A continuous lumping approach. Fuel 2015;139:133-43. doi:10.1016/j.fuel.2014.08.032.

[17] Becker PJ, Celse B, Guillaume D, Costa V, Bertier L, Guillon E, et al. A Continuous Lumping Model for Hydrocracking on a Zeolite Catalysts: Model Development and Parameter Identification. Fuel n.d.;xx:xx.

[18] Catalyse acido-basique. - MARCILLY Christian. 2003. 
[19] Weitkamp J. Catalytic Hydrocracking-Mechanisms and Versatility of the Process. ChemCatChem 2012;4:292-306. doi:10.1002/cctc.201100315.

[20] Froment GF. On fundamental kinetic equations for chemical reactions and processes. Curr Opin Chem Eng 2014;5:1-6. doi:10.1016/j.coche.2014.02.002.

[21] Marcilly C. Catalyse Acido-Basique - Volume 1 \& 2. Paris: Editions Technip; 2003.

[22] Qader SA, Hill GR. Hydrocracking of Petroleum and Coal Oils. Ind Eng Chem Process Des Dev 1969;8:462-9. doi:10.1021/i260032a005.

[23] Sanchez S, Rodriguez MA, Ancheyta J. Kinetic Model for Moderate Hydrocracking of Heavy Oils. Ind Eng Chem Res 2005:9409-13.

[24] Lababidi HMS, Chedadeh D, Riazi MR, Al-Qattan A, Al-Adwani HA. Prediction of product quality for catalytic hydrocracking of vacuum gas oil. Fuel 2011;90:719-27. doi:10.1016/j.fuel.2010.09.046.

[25] Lababidi HMS, AlHumaidan FS. Modeling the hydrocracking kinetics of atmospheric residue in hydrotreating processes by the continuous lumping approach. Energy \& Fuels 2011;25:1939-49. doi:10.1021/ef200153p.

[26] Stangeland BE. Kinetic Model for the Prediction of Hydrocracker Yields. Ind Eng Chem Process Dev 1974;13:71-6.

[27] Baltanas M a., Froment GF. Computer generation of reaction networks and calculation of product distributions in the hydroisomerization and hydrocracking of paraffins on Pt-containing bifunctional catalysts. Comput Chem Eng 1985;9:71-81. doi:10.1016/0098-1354(85)87005-8.

[28] Froment GF. Kinetics of the hydroisomerization and hydrocracking of paraffins on a platinum containing bifunctional Y-zeolite. Catal Today 1987;1:455-73. doi:10.1016/09205861(87)80009-3.

[29] Hillewaert LP, Dierickx JL, Froment GF. Computer generation of reaction schemes and rate equations for thermal cracking. AIChE J 1988;34:17-24. doi:10.1002/aic.690340104.

[30] Van Raemdonck KK, Froment GF. Fundamental kinetic modeling of hydroisomerization and hydrocracking on noble metal-loaded zeolites. II. The elementary cracking steps. AIChE Meet., 1989.

[31] Vynckier E, Froment G. Modeling of the kinetics of complex processes based upon elementary steps. In: Astarita G, Sandler SI, editors. Kinet. Thermodyn. Lumping Multicomponent Mix., Amsterdam: Elsevier Science Publishers; 1991.

[32] Cochegrue H, Gauthier P, Verstraete JJ, Surla K, Guillaume D, Galtier P, et al. Reduction of Single Event Kinetic Models by Rigorous Relumping: Application to Catalytic Reforming. Oil Gas Sci Technol - Rev d’IFP Energies Nouv 2011;66:367-97. doi:10.2516/ogst/2011122.

[33] Surla K, Guillaume D, Verstraete JJ, Galtier P. Kinetic Modeling using the Single-Event Methodology: Application to the Isomerization of Light Paraffins. Oil Gas Sci Technol - Rev d’IFP Energies Nouv 2011;66:343-65. doi:10.2516/ogst/2011119. 
[34] Kumar H. Single Event kinetic modellling of the hydrocracking of paraffins. A\&M Univeristy, Texas, 2004.

[35] Valéry E. Application de la théorie des événements constitutifs à l’hydrocraquage des paraffines lourdes. Universite Lyon 1 (IFPEN), 2002.

[36] Van de Runstraat A, van Grondelle J, van Santen RA. Microkinetics Modeling of the Hydroisomerization of n -Hexane. Ind Eng Chem Res 1997;36:3116-25. doi:10.1021/ie960661y.

[37] Holló A, Hancsók J, Kalló D. Kinetics of hydroisomerization of C5-C7 alkanes and their mixtures over platinum containing mordenite. Appl Catal A Gen 2002;229:93-102. doi:10.1016/S0926-860X(02)00018-2.

[38] Dutriez T, Courtiade M, Thiébaut D, Dulot H, Hennion M-C. Improved hydrocarbons analysis of heavy petroleum fractions by high temperature comprehensive two-dimensional gas chromatography. Fuel 2010;89:2338-45. doi:10.1016/j.fuel.2009.11.041.

[39] Dutriez T, Thiébaut D, Courtiade M, Dulot H, Bertoncini F, Hennion M-C. Application to SFC-GC $\times$ GC to heavy petroleum fractions analysis. Fuel 2013;104:583-92. doi:10.1016/j.fuel.2012.04.048.

[40] Hudebine D. Reconstruction moléculaire de coupes pétrolières. Ecole normale supérieure, Lyon, 2003.

[41] Hudebine D, Verstraete J, Chapus T. Statistical Reconstruction of Gas Oil Cuts. Oil Gas Sci Technol - Rev d’IFP Energies Nouv 2011;66:461-77. doi:10.2516/ogst/2009047.

[42] Hudebine D, Verstraete JJ. Molecular reconstruction of LCO gasoils from overall petroleum analyses. Chem Eng Sci 2004;59:4755-63. doi:10.1016/j.ces.2004.09.019.

[43] Hudebine D, Verstraete JJ. Reconstruction of Petroleum Feedstocks by Entropy Maximization. Application to FCC Gasolines. Oil Gas Sci Technol 2011;66:437-60. doi:10.2516/ogst/2011110.

[44] Benson SW, Buss JH. Additivity Rules for the Estimation of Molecular Properties. Thermodynamic Properties. J Chem Phys 1958;29:546. doi:10.1063/1.1744539.

[45] Pereira de Oliveira LC. Development d'une Methodologie de Modelisation cinetique de Procedes de Raffinage Traitant des Charges Lourdes. Ecole Normale Superieure de Lyon, 2013.

[46] Korre SC, Neurock M, Klein MT, Quann RJ. Hydrogenation of polynuclear aromatic hydrocarbons. 2. quantitative structure/reactivity correlations. Chem Eng Sci 1994;49:4191210. doi:10.1016/S0009-2509(05)80015-6.

[47] Dutriez T, Courtiade M, Thiébaut D, Dulot H, Bertoncini F, Vial J, et al. High-temperature two-dimensional gas chromatography of hydrocarbons up to nC60 for analysis of vacuum gas oils. J Chromatogr A 2009;1216:2905-12. doi:10.1016/j.chroma.2008.11.065.

[48] Sinoquet D, Langouet H. SQA: a generic trust region derivative free optimization method for black box industrial applications. ICCOPT Int. Conf. Contin. Optim., 2013. 
[49] McKay MD, Beckman RJ, Conover WJ. Comparison of Three Methods for Selecting Values of Input Variables in the Analysis of Output from a Computer Code. Technometrics 1979;21:239_ 45. doi:10.1080/00401706.1979.10489755. 